Article

\title{
Experiences and Statistical Evaluation of Serious Undesirable Effects of Cosmetic Products in the EU
}

\author{
Andreas Butschke *, Astrid Droß, Katja Dünnebier, Ines Laube and Ariane Weiler \\ Federal Office on Consumer protection and food safety (BVL), Mauerstr. 39-42, 10117 Berlin, Germany; \\ astrid.dross@bvl.bund.de (A.D.); katja.duennebier@bvl.bund.de (K.D.); ines.laube@bvl.bund.de (I.L.); \\ ariane.weiler@bvl.bund.de (A.W.) \\ * Correspondence: 105@bvl.bund.de; Tel.: +49-30-184-4410-500
}

Academic Editors: Lidia Sautebin and Immacolata Caputo Received: 30 May 2016; Accepted: 7 July 2016; Published: 18 July 2016

\begin{abstract}
The Council of Europe created an outline for a vigilant system of undesirable effects of cosmetic products in 2006. In 2013, some of those aspects were included in the European Cosmetics Regulation (EC) 1223/2009. Since then, serious undesirable effects (SUEs), which are the tip of the iceberg of all undesirable effects of cosmetic products, have to be reported to competent authorities. Neglecting the first phase of establishing the system, we have about two years of experience regarding the notification of SUEs. This notification system is based on a huge amount of cases that allow us to identify occurring problems at an early stage through a signal of increased reported cases for a certain product. It has already been shown that the system is able to identify products that have the potential to cause health risks even if they seem to comply with the legal requirements and the safeguard clause was applied. Until May 2016, 680 cases of SUEs were shared in the EU. The statistics of SUEs indicate that hair dyes and skin care products are the product types that cause the most SUEs. Almost $80 \%$ of all SUEs occurred in the head area, especially the skin of the face was affected.
\end{abstract}

Keywords: serious undesirable effects; cosmetics; statistical evaluation; cosmetic legislation; Regulation (EC) 1223/2009

\section{Introduction}

The legal framework for cosmetic products in the European Union is Regulation (EC) No. 1223/2009 [1], which has been fully in force since July 2013. The regulation creates EU-wide harmonised regulatory standards to ensure a high safety level of cosmetic products in the European market and better protection of the consumer. Cosmetic products may cause undesirable effects to the consumer (e.g., itching, redness, skin swelling or irritation, allergic reaction), even though the product complies with the existing legislation.

One core element to guarantee a high level of consumer protection in the European Union is the product information file (PIF) that has to be created and archived by the responsible person, which is the person or company that produces or imports this cosmetic product. Since 1995, this PIF has also contained a safety assessment created by an expert as well as reports about undesirable effects caused by the product. Among others, the notification of undesirable effects from cosmetic products was introduced with the new regulation in July 2013 for all EU Member States, even if some Member States established a national system previously [2]. According to Article 23 of the Cosmetic Regulation [1], responsible persons and distributors have the legal obligation to report all serious undesirable effects (SUEs) to the competent authorities of the Member States.

SUEs are defined in Cosmetic Regulation Article 2 (1) (p) as "undesirable effects which result in temporary or permanent functional incapacity, disability, hospitalization, congenital anomalies or an immediate vital risk or death" [1]. The goal is to establish a cosmetovigilance system enabling the 
identification of potential substances with negative effects on human health [3]. For this, a collaboration of all stakeholders (responsible persons, distributors, doctors, pharmacists, authorities and Member States) is needed to collect all SUE cases and adequate data.

Consumers or the attending medical professionals can inform the producer, importer, distributor or also a public authority about the undesired effects. The person that receives the information has to make a causality assessment and submit the case description with harmonised notification forms to the competent authorities. The case descriptions are shared among the competent authorities of the EU Member States. The German Federal Office on Consumer Protection and Food Safety (BVL) is compiling statistics about all cases in the EU, which is the basis of the figures in this article.

In 2006 the resolution of the Council of Europe intended to establish the following aspects in a cosmetovigilance system [4]:

(1) "monitoring the occurrence and evaluating the risk of undesirable effects caused by cosmetic products;

(2) reporting and recording of undesirable effects;

(3) establishing and taking corrective measures;

(4) conducting complementary assessments or studies relating to the safety of use of cosmetic products;

(5) identifying cosmetic products and/or ingredients which can present a risk for consumers' health."

Pharmacovigilance is defined by the World Health Organisation (WHO) as "the science and activities relating to the detection, assessment, understanding and prevention of adverse effects or any other possible drug-related problems" [5]. Until now, a comparable approach for cosmetovigilance has not been defined in the European cosmetic legislations. Only one aspect of a vigilance system, the reporting of serious cases to the competent authorities, is covered by the legislation. All further steps of assessment, understanding and prevention of such effects are left to the responsibility of the dedicated national authority, regardless if these are market surveillance authorities, vigilance experts or medical experts from the university. That means that the resolution of the Council of Europe was implemented in the European legislation at the lowest possible level: the reporting of cases. Nevertheless, the reporting of cases is an effort that should not remain unused. Due to the additional efforts of all participants, the system has already shown its potential for providing added value for the enhancement of cosmetic product safety.

\section{Results}

Since the obligation to report SUEs started in July 2013, a total of 680 SUE cases from 23 Member States were reported up until May 2016. In 2013, only a few member states shared their data among all Member States, since some national processes were still in the establishment phase. Therefore, for representative reasons, only data from 2014 and 2015 will be further considered and discussed in this paper.

In those two years, 529 SUE cases were reported in the EU, with 35\% being confirmed by medical professionals. In most cases, the consumer has reported the company that is responsible for the products and is labelled with its address on all products. It was reported that $7 \%$ of all cases occurred during professional usage, e.g., at the hairdresser, but only the half of these cases were reported to or from the cosmetic professional. The real information flow from the affected consumer to the competent authority is shown in Figure 1. 


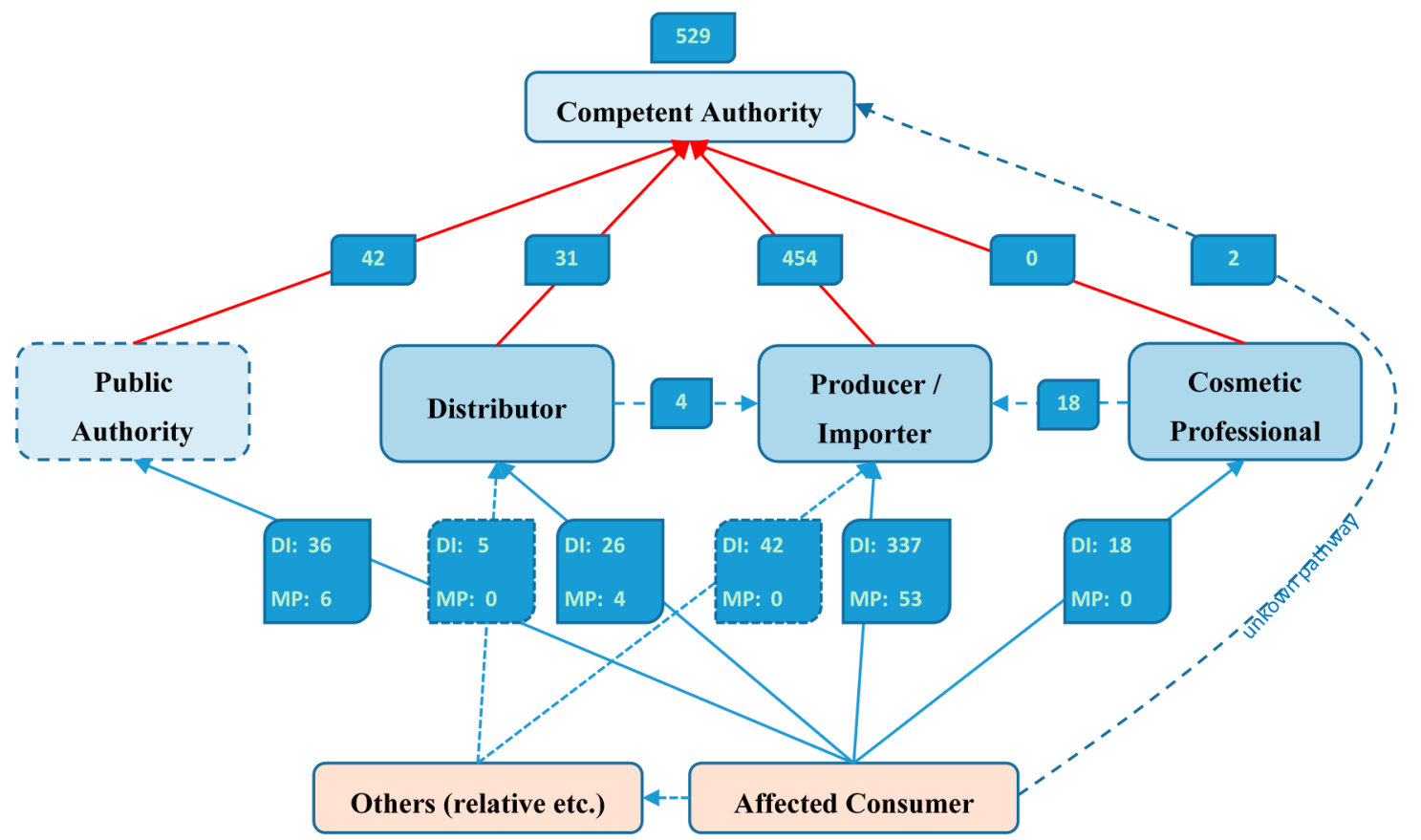

Figure 1. Pathways of information. The consumer has several possibilities to forward the information about his/her SUE: directly (DI) or via medical professionals (MP). Mostly the consumer is addressing the undesirable effect to the responsible person (producer/importer). The receiving organisation has to report the SUE case with the harmonised format to the competent authority.

The majority of the cases involved reports of functional incapacity $(68 \%)$ such as inability to work or reduced quality of life, e.g., due to vision impairment, followed by hospitalisation $(26 \%)$ and immediate vital risk (3.5\%). The criteria "congenital anomalies" had not been reported at all. The causality between the SUE and the suspected product was assessed in two-thirds of all cases at least as "likely", which is shown in Table 1.

Table 1. The number of cases with their relation of causality vs. seriousness. In $74 \%$ of all cases the causality is assessed as "likely" or "very likely". The guidelines do not require reporting of cases with excluded causality or other/unknown seriousness criteria.

\begin{tabular}{ccccccccc}
\hline Seriousness & Total & $\begin{array}{c}\text { Very } \\
\text { Likely }\end{array}$ & Likely & $\begin{array}{c}\text { Not Clearly } \\
\text { Attributable }\end{array}$ & Unlikely & Excluded & Un-Assessable Unknown \\
\hline Functional & 361 & 48 & 224 & 61 & 6 & 2 & 12 & 8 \\
Incapacity & 139 & 9 & 87 & 29 & 5 & - & 6 & 3 \\
Hospitalisation & 5 & 1 & 3 & - & 1 & - & - & - \\
Disability & 18 & 1 & 14 & 2 & - & 1 & - & - \\
Immediate & 18 & - & - & - & 1 & - & 1 & - \\
vital risk & 2 & 2 & 1 & - & - & - & 1 & - \\
Death & 4 & $51(12 \%)$ & $329(62 \%)$ & $92(17 \%)$ & $13(2.5 \%)$ & $3(0.6 \%)$ & $20(3.8 \%)$ & $11(2.1 \%)$ \\
\hline Others & 529 & $61 \%$ & & & & &
\end{tabular}

Regarding the SUE notification by product type as shown in Figure 2, skin care products are leading the statistics with $34 \%$, followed by hair dye products $(28 \%)$, other hair and skin products ( $8 \%$ each), and nail varnish/remover products $(6 \%)$. It is of interest that the relation between the seriousness criteria of hospitalisation, functional incapacity and immediate vital risk is different for hair dye products and skin care products. Especially SUEs with hair dye products result in hospitalisation at a relatively high rate. 


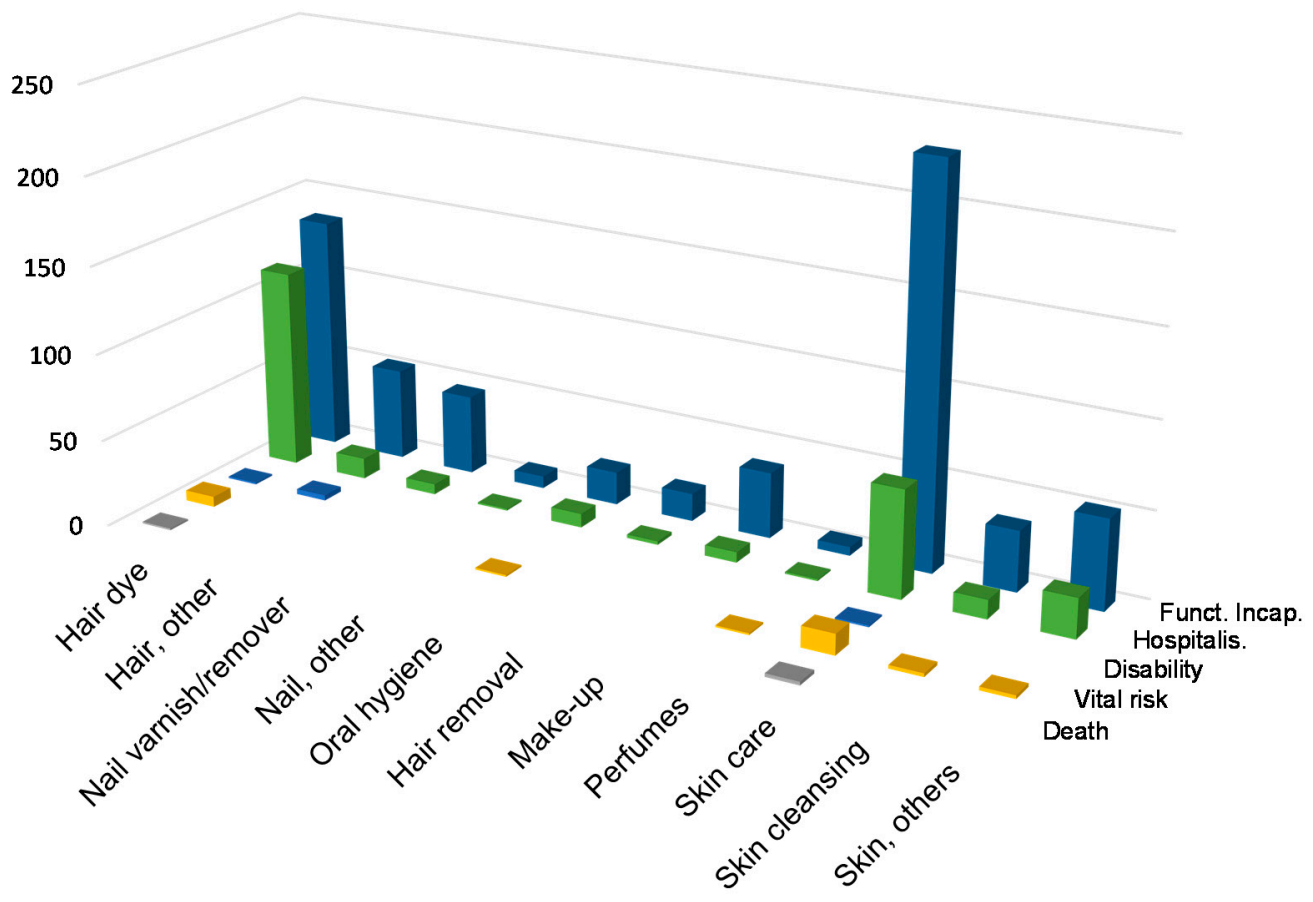

Figure 2. Number of cases by product type related to the seriousness criteria. Hair dye as well as skin care products are standing out.

A high amount of cases concerning hair dyes was not surprising since the sensitising potential of $p$-phenylenediamine (PPD) and its derivatives is well known. Allergic contact dermatitis caused by PPD is common among all consumer groups and the prevalence of PPD sensitisation in Europe is about $4 \%$ [6]. On the other hand, the high amount of cases concerning skin care products seems to be unexpected. However, even if skin care products might not generally contain substances with high sensitisation potential, they are often used and are widespread in leave-on products. When comparing case numbers of different product types or products, the market share also has to be considered. Reliable information on the market share is not always available and the SUE guidelines currently do not require the submission of specifications about the market share.

SUEs mainly occur in the facial area (57\%) and in about $65 \%$ of cases, the skin and an additional $10 \%$ of the scalp was affected. In $4 \%$ of all cases, the respiratory tract was affected ( $43 \%$ of others). Also, the impairment of the respiratory tract is caused primarily by hair dyes and skin care products in $86 \%$ of cases. The other affected body areas are shown in Figure 3. Concerning the 390 cases where the causality was assessed by the companies or the authorities as likely or very likely, in $45 \%$ of those cases only the intended application area was affected, in a further $44 \%$ of cases other body areas were also affected in addition to the application area, and in $9 \%$ of cases only body areas other than the application area were affected.

Based on the submitted information it can be concluded that most effects are contact dermatitis of unspecified, allergic or irritant nature (Table 2). It has to be pointed out that a diagnosis of an allergic effect means that only in very few cases this diagnosis was confirmed by a dermatologist or allergic expert using patch tests. Therefore, it can be assumed that a false, too-high number of allergic reactions have been reported. Allergic diagnostics is almost an additional medical treatment that is mostly not indicated in the acute phase of the disease to prevent jeopardizing the consumer's health. Sometimes an intended patch test was done, but the results were not submitted or the consumer no longer had an interest in further medical treatment after recovery. Unfortunately, this missing information about test results is leading to a lack of knowledge in this notification system about substances that can trigger SUEs. Consequently, the SUE case statistics are not suited to deriving any conclusion about the ratio between allergic and irritant effects occurring with the use of cosmetics. 


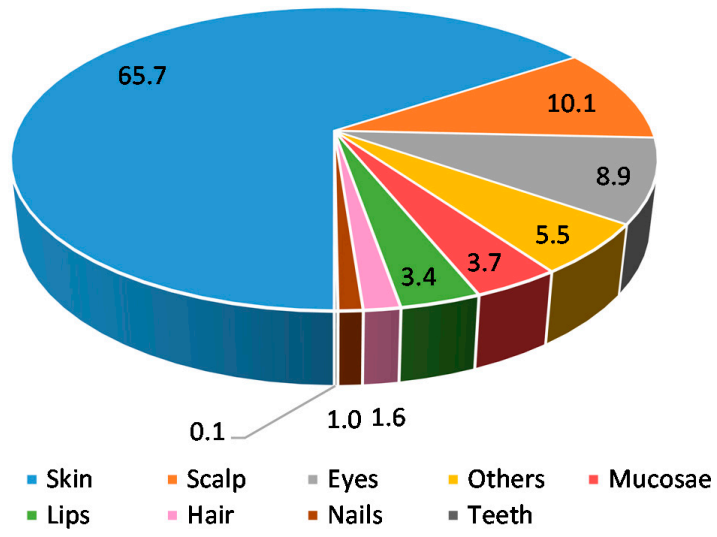

(a)

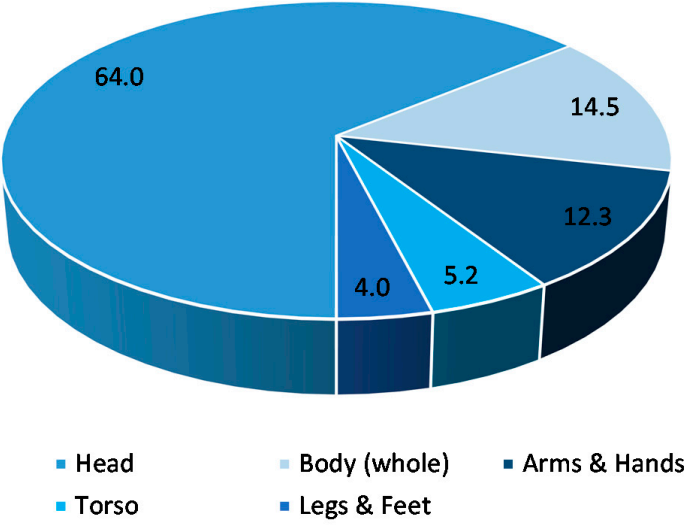

(b)

Figure 3. Location of the occurred SUE in percent (\%) of all affected body parts: (a) shows the share of the main body parts and (b) shows the detailed share of the affected skin parts.

Table 2. Amount of SUE cases related to categorised diagnosis made by BVL in accordance to the ICD-10 classification [7] on the basis of reported diagnosis or further description of the effect, symptoms, treatment or complementary investigation.

\begin{tabular}{ccc}
\hline Body Area & Diagnosis (ICD-10) & Share (\%) \\
\hline Skin & Contact dermatitis, unspecified & 37.1 \\
Skin & Contact dermatitis, allergic & 34.4 \\
Systemic & Anaphylactic shock, unspecified/Anaphylaxis & 6.3 \\
Skin & Contact dermatitis, irritant & 3.8 \\
Skin & Urticaria & 2.3 \\
Eye & Other disorder of eye and adnexa & 2.1 \\
Eye & Conjunctivitis, unspecified & 1.9 \\
Mouth & Irritation oral mucosa & 1.9 \\
Skin & Other skin changes & 1.3 \\
Systemic & Systemic, others & 1.1 \\
Systemic & Diseases of the respiratory system & 1.1 \\
Nails & Onycholysis & 1.1 \\
Various & Others & 5.5 \\
\hline
\end{tabular}

\section{Discussion}

It must be understood that this is not a highly sophisticated system with deep case-by-case verification using appropriate tests conducted by dermatologists or other medical experts in the concerned field of effect. The purpose of the obligation of notification by companies is the monitoring of a huge amount of cases and to identify problems with certain products or product categories by 
signals of accumulating cases. The system aims to transport relevant information at an early stage to the competent authorities to be able to identify upcoming problems and to be in a good position to prevent the consumers from further health risks through effective cooperation between companies and competent authorities. The obligation to report SUEs should guarantee that information about SUEs will come to the knowledge of the competent authorities and the responsible company even if it is addressed by the consumer to the distributor, cosmetic professional or elsewhere.

The reporting of undesirable effects to the competent authorities in Sweden, Denmark and Finland has shown that a high amount of cases (39 SUE notifications) were raised in a short time for a certain product group from one company. The product, acrylate-containing UV-curing nail polish for non-professional use, seems to be in accordance with the current legislation, but the signal of a large amount of undesired effects in relation to the supposed market share of the product indicates that this cosmetic product is not safe for the consumer in its normal usage. This may be caused by a lack of declarations or warnings, a combination of substances that results in unpredictable effects or the presence of impurities or contaminations. Even if the product meets the requirements of the Cosmetic Regulation, the safeguard clause of Article 27 of the Cosmetic Regulation [1] gives competent authorities the option to take appropriate provisional measures regarding the products concerned.

This helps to protect the consumer's health also if a specific reason for the undesired effect was not identified on a scientific basis. The identification of the inducing substance, mixture of substances or usage of the product has to be done subsequently to justify the measures under consultation of the involved companies, other Member States and the Scientific Committee on Consumer Safety (SCCS) [8].

On a second level, beyond the observation of certain products, is the identification of product types or substances where high amounts of SUEs can be observed. The statistical evaluation could be the basis for management decisions to enhance precautionary consumer protection, e.g., to reflect upon special substance combinations, application areas for certain substances or an adaptation of warnings or consumer information. Only in $8 \%$ of the reported cases were the substances or substance groups (such as in hair dyes) identified. PPD, methylisothiazolinone (MI) and fragrances were specified in multiple cases, which is in good correlation with epidemiological studies $[9,10]$.

Therefore, the system is suited to identifying unknown potential health risks and to initiating appropriate measures:

(1) to identify the scientific background and to evaluate the risk for human health;

(2) to focus on comparable products in market surveillance activities;

(3) to prevent similar undesirable effects in the future.

All cases in which the assessment does not result in an excluded causal relation have to be reported, even if the causality is not assessable or unlikely. Also, death as an undesirable effect was already reported two times, since it could not be excluded on the basis of the prescribed causality assessment, but it must be considered that the causality in the already reported cases was unlikely or not assessable. Immediate death as a result of the hazardousness of a cosmetic product is in general hardly conceivable, but it is imaginable as a result of an untreated anaphylactic shock, which has to be considered as an immediate vital risk.

The notification of an SUE on a certain product does not necessarily indicate a serious risk or non-compliance of the product. Only in a very few cases was the product found to be not in compliance with the legislation. In some cases, the companies have taken voluntary measures to substitute a substance, e.g., such as the preservative MI with a known high sensitisation prevalence $[11,12]$ with substances with a lower sensitising potential.

To establish a vigilance system is not done only by bringing an obligation of notification into force. The possibility or obligation for a notification has to be known to all stakeholders from consumers to companies, medical doctors and also the competent authorities that may receive a type of unstructured information about a more or less serious undesired effect. A further step that should have been 
established is the compilation of all cases to be able to get signals on the basis of data from all EU Member States. Finally, there should be a committee that reviews some cases and the statistics for recommendations to enhance the product safety according to suitable management processes.

Beside the need to establish a general structure for the notification, there are some special aspects to be considered for cosmetics that complicate the identification of substances that have the potential to cause undesired effects.

In contrast to pharmaceuticals, cosmetic products do not have to be tested in mandatory clinical studies to prove their efficacy and safety. In such studies, adverse effects already occur in the pre-marketing phase of a product and results are assessed by experts under clear, arranged circumstances. For cosmetic products, these studies are only required if claims about the tolerability of a product are intended.

Most pharmaceuticals are well-known carrier substances combined with one or only very few other pharmaceutical active substances. The assessment of the trigger of an adverse effect can be identified by focussing on these few substances in a pharmaceutical product. In contrast to pharmaceuticals, cosmetic products are a composition of a broad variety of different substances where a lot of them are, in principal, able to cause undesirable effects based on the individual predisposition of the consumer. That means that even if the causality assessment resulted in a likely relation between a product and a SUE case, there is still a way to go for the identification of the inducing substance.

As a reason for SUEs due to cosmetics, mostly contact dermatitis of an unspecified, allergic or irritant nature was reported. Products that have been used even for a long time without problems can cause sensitization and be the cause of an SUE. To establish an allergic origin, a patch test has to be conducted. Normally, several cosmetic products are used in parallel, several of them also in the same application area. This is reflected in $15 \%$ of the cases where more than one product was suspected of causing the SUE. Sometimes a consumer is exposed the first time to several cosmetic products at the same time, e.g., at the hairdresser, in a cosmetics studio, or at a hotel. All products that are also used in the area of the local adverse effects have to be considered in the origin of the SUE. In one case, 14 different cosmetic products were actually under suspicion. In addition to cosmetics, other products such as detergents or cleaning agents that are used in the household are getting in contact with the skin and must also be considered in the analysis of the causes. Finally, foodstuffs could also lead to a systemic availability of substances and to a dermal reaction at several parts of the body after intestinal incorporation [13]. All these aspects may result in a false positive or false negative assumed correlation between an SUE and a certain cosmetic product.

The identification of certain substances can only be realised by allergy tests such as a patch test with relevant cosmetic ingredients. This test has to be carried out by a dermatologist who needs all the relevant ingredients as single substances or adequate mixtures. At least substances from the European baseline patch test series [14-16] should be tested, and they contain different fragrance mixes as well as preservatives and other relevant substances. Preferably the product as is could be included in the test.

The reporting of the adverse effects of pharmaceuticals is an ethical commitment for most physicians. On the other hand, the reporting of the undesirable effects of cosmetics is mostly unknown or in general not recognised as serious, since it is "only cosmetics", regardless of the potential for severe health effects that could occur. Nevertheless, in the future it is hoped that the amount of substantiated reports from medical professionals will increase.

It can be observed that one crucial step in the process of SUE notifications is the causality assessment. Annex I of the SUE guidelines [17] specifies the comprehensive process of causality assessment on about 10 pages. To tackle the problem that this essential assessment is too complicated for several companies or authorities, a spreadsheet following the decision tree [18] from the Annex I was designed and is provided as assistance by the BVL [19]. The spreadsheet has a short assessment procedure that is useful if only rare information was provided about a case and it offers a comprehensive assessment procedure if substantial medical information is available. The spreadsheet is online available for free on the website of the BVL [19]. 


\section{Conclusions}

This new system of mandatory notification of SUEs for companies, regardless of their function (producer, importer, distributor or cosmetician), is in its third year and is still in the process of being established. Until now, not all players were aware about their obligation to notify, check and forward information about SUEs. Furthermore, there is still a lack of qualified information about the substances that caused the undesirable effects.

Currently, the system is a system of great mass that is able to identify signals of repeated cases with the same products or products of the same type or those made by the same company. In this capacity, the system has already been proven effective. Nevertheless, the system has the potential to provide a case-by-case evaluation of certain products and substances similar to the pharmacovigilance system.

Acknowledgments: The work is an output of the governmental activities of the national contact point for SUE in Germany and solely financed by public funding.

Author Contributions: Ariane Weiler and Andreas Butschke have made the scientifically and statistical evaluation; Astrid Droß has coordinated the work and Ines Laube and Katja Dünnebier have supported the work with ideas, figures and proofreading.

Conflicts of Interest: The authors declare no conflict of interest.

\section{Abbreviations}

The following abbreviations are used in this manuscript:

$\begin{array}{ll}\text { BVL } & \text { Bundesamt für Verbraucherschutz und Lebensmittelsicherheit/Federal } \\ \text { EU } & \text { Office of Consumer Protection and Food Safety } \\ \text { MI } & \text { European Union } \\ \text { PIF } & \text { Methylisothiazolinone } \\ \text { PPD } & \text { Product information file } \\ \text { SCCS } & p \text {-Phenylenediamine } \\ \text { SUE } & \text { Scientific Committee on Consumer Safety of the European Commission } \\ \text { WHO } & \text { Serious undesirable effect }\end{array}$

\section{References}

1. Regulation (EC) No. 1223/2009 of the European Parliament and of the Council of 30 November 2009 on Cosmetic Products (Recast). Available online: http:/ / eur-lex.europa.eu/LexUriServ/LexUriServ.do?uri=OJ: L:2009:342:0059:0209:en:PDF (accessed on 30 May 2016).

2. Vigan, M.; Castelain, F. Cosmetovigilance: Definition, regulation and use "in practice". Eur. J. Dermatol. 2014, 24, 643-649. [PubMed]

3. Sautebin, L. A cosmetovigilance survey in Europe. Pharmacol. Res. 2007, 55, 455-460. [CrossRef] [PubMed]

4. Council of Europe. Resolution ResAP 1 on a Vigilance System for Undesirable Effects of Cosmetic Products ("COSMETOVIGILANCe") in Europe in Order to Protect Public Health; Council of Europe: Strasbourg, France, 2006.

5. World Health Organization (WHO). The Safety of Medicines in Plublic Health Programmes_Pharmacovigilance an Essential Tool. World Health Organisation, 2006. Available online: http://www.who.int/medicines/areas/quality_safety/safety_efficacy/Pharmacovigilance_B.pdf (accessed on 30 May 2016).

6. Schuttelaar, M.-L.A.; Vogel, T.A.; Rui, F.; Kręcisz, B.; Chomiczewska-Skora, D.; Kieć-Świerczyńska, M.; Uter, W.; Filon, F.L. ESSCA results with the baseline series, 2002-2012: $p$-Phenylenediamine. Contact Dermat. 2016. [CrossRef] [PubMed]

7. World Health Organization (WHO). International Statistical Classification of Diseases and Related Health Problems 10th Revision (ICD-10), 2016. Available online: http://apps.who.int/classifications/icd10/ browse/2016/en (accessed on 30 May 2016).

8. European Commission. Call for Data on Ingredients: "Di-HEMA Trimethylhexyl Dicarbamate", "HEMA" and the Class of Compounds "Urethane acrylates". Available online: http:/ / ec.europa.eu/growth/toolsdatabases/newsroom/cf/itemdetail.cfm?item_id=8719\&lang=en (accessed on 30 May 2016). 
9. Zaragoza-Ninet, V.; Encinas, R.B.; Vilata-Corell, J.J.; Pérez-Ferriols, A.; Sierra-Talamantes, C.; Esteve-Martínez, A.; de la Cuadra-Oyanguren, J. Allergic Contact Dermatitis Due to Cosmetics: A Clinical and Epidemiological Study in a Tertiary Hospital. Actas Dermosifiliogr. 2016, 107, 329-336. [CrossRef] [PubMed]

10. Schnuch, A.; Uter, W.; Geier, J.; Lessmann, H.; Frosch, P.J. Sensitization to 26 fragrances to be labelled according to surrent European regulation. Contact Dermat. 2007, 57, 1-10. [CrossRef] [PubMed]

11. Scientific Committee on Consumer safety (SCCS). Opinion of the Scientific Committee on Consumer safety (SCCS)-Opinion on the safety of the use of Methylisothiazolinone (MI) (P94), in cosmetic products (sensitisation only). Regul. Toxicol. Pharmacol. 2016, 76, 211-212.

12. Aerts, O.; Baeck, M.; Constandt, L.; Dezfoulian, B.; Jacobs, M.C.; Kerre, S.; Lapeere, H.; Pierret, L.; Wouters, K.; Goossens, A. The dramatic increase in the rate of methylisothiazolinone contact allergy in Belgium: A multicentre study. Contact Dermat. 2014, 71, 41-48. [CrossRef] [PubMed]

13. Fabbro, S.K.; Matthew, J.Z. Systemic Contact Dermatitis to Foods: Nickel, BOP, and More. Curr. Allergy Asthma Rep. 2014, 14, 1-7. [CrossRef] [PubMed]

14. Bruze, M.; Condé-Salazar, L.; Goossens, A.; Kanerva, L.; White, I.R. Thoughts on sensitizers in a standard patch test series. Contact Dermat. 1999, 41, 241-250. [CrossRef]

15. Bruze, M.; Goossens, A.; Isaksson, M. Recommendation to increase the test concentration of MCI/MI in the European baseline patch test series-On behalf of the European Society of Contact Dermatitis and the European Environmental and Contact Dermatitis Research Group. Contact Dermat. 2014, 71, 35-40. [CrossRef] [PubMed]

16. European Society of Contact Dermatitis. Baseline Series. Available online: http://www.escd.org/aims / standard_series/index.html (accessed on 30 May 2016).

17. European Commission. Annex 1: Causality Assessment of Undesirable Effects Caused by Cosmetic Products to Guidance Document on Administrative Sooperation in the Area of Market Surveillance of Cosmetic Products. Available online: http:/ /ec.europa.eu/DocsRoom/documents/13251/ (accessed on 30 May 2016).

18. Bons, B.; Audebert, F.; Bitaudeau, C.; Cachin, N.; Colson, L.; Farr, C.; Fix, L.A.; Gilmour, N.; Gorni, R.; Griffiths, M.; et al. Assessment of undesirable events in cosmetic market surveillance: Background, description and use of a causality assessment method in cosmetovigilance. Regul. Toxicol. Pharmacol. 2010, 58, 349-353. [CrossRef] [PubMed]

19. Bundesamt für Verbraucherschutz und Lebensmittelsicherheit (BVL). SUE Causality Assessment Assistance Spreadsheet (MS Excel). Available online: www.bvl.bund.de/sue-causality (accessed on 30 May 2016). 